\title{
Recurrent Vulvo-Vaginal Candidiasis: Diagnostic and Management Challenges in a Developing Country Context
}

\begin{abstract}
Vulvo-vaginal candidiasis (VVC) is a very common cause of vaginal symptoms in women, with at least $75 \%$ of them experiencing one episode in their reproductive years, $5-10 \%$ of who experience recurrences (RVVC) i.e. $\geq 4$ specific episodes within one calendar year. It's associated with significant morbidity, affecting the woman's quality of life as well as sexual function.

The pathogenesis of RVVC remains unresolved to date. Majority of the patients are healthy, immunocompetent and have no discernible predisposing or causative factors. There are controversies regarding the identified risk factors, with some studies showing an association and others not. Diagnosis of RVVC is a challenge since its clinical features are not pathognomonic thereof and current laboratory tests are not capable of discriminating between healthy carrier states and symptomatic infections. Successful treatment may be achieved with oral or topical agents, which are equally effective. However, even long-term therapy does not prevent recurrences. Repeated treatment might select and induce drug resistance and a shift toward more resistant Candida species, as well as lead to non-compliance with treatment.

Although diagnosis and management or RVVC are major challenges globally they are much more so in a developing country context because of various health care delivery related constraints. It is often over-diagnosed or misdiagnosed, leading to inappropriate treatment especially in resource-constrained developing countries.
\end{abstract}

Research Article
Volume 7 Issue 5 - 2017
Valentino M Lema*
The Aga Khan University, Kenya
*Corresponding author: Valentino M Lema, Professor of
Obstetrics and Gynaecology, Honorary Faculty, The Aga
Khan University, Nairobi. Kenya, Email: vmlema@gmail.com;
sreprohealth@gmail.com
Received: July 10, 2017 | Published: August 09, 2017

Abbreviations: VVC: Vulvovaginal Candidiasis; BV: Bacterial Vaginosis; RVVC: Recurrent Vulvovaginal Candidiasis

\section{Introduction}

Vulvovaginal candidiasis (VVC) is a frequent and common distressing disease affecting women of all ages and across social strata globally. It is the second most common cause of vaginal infections after bacterial vaginosis (BV) [1]. Estimates indicate that $70 \%-75 \%$ of women of childbearing age worldwide experience at least one episode during their lifetime, and 5\%-10\% of women with a primary episode of VVC experience frustrating recurrent infections (RVVC) [2], defined as at least three-four specific episodes within one year [3,4]. VVC is rare before puberty, its incidence increasing dramatically in the second decade of life, coinciding with the onset of sexual activity [5]. About $54.7 \%$ of women will experience one episode by age 25 [5]. It is classified as "uncomplicated and complicated", which is now internationally accepted $[7,8]$. It is also classified as sporadic (acute) and recurrent based on the frequency of the infectious episodes [3]. RVVC is part of the complicated vulvo-vaginal candidiasis (Table 1).

Recurrent vulvovaginal candidiasis (RVVC) is defined as four or more specific episodes of VVC or at least three episodes not related to antibiotic therapy, within twelve calendar months, with at least partial resolution of symptoms between episodes and a positive microscopy or culture on at least two occasions when symptomatic $[7,9,10]$. There are two forms of RVVC: primary
RVVC which is idiopathic with unknown predisposing factors. This occurs in otherwise healthy, immunocompetent women, majority of who have no discernible precipitating or causative factors [11]. Secondary RVVC is the occurrence of frequent episodes of acute VVC because of certain predisposing factors such as hormone replacement therapy or diabetes mellitus [12].

Table 1: Classification of Genital Candidiasis.

\begin{tabular}{|c|c|c|}
\hline Feature & Uncomplicated & Complicated \\
\hline Severity & Mild or Moderate & Severe \\
\hline Frequency & Sporadic & Recurrent \\
\hline Organism & Candida albicans & Candida spp., except C. albicans \\
\hline Host & Normal & $\begin{array}{c}\text { Abnormal, (e.g. uncontrolled } \\
\text { diabetes mellitus) }\end{array}$ \\
\hline
\end{tabular}

The primary pathology in genital candidiasis is inflammation of the vulva and vagina secondary to an overgrowth of Candida. The resultant symptoms and clinical signs are not only non-specific but also not sensitive, i.e. not pathognomonic for candidiasis $[13,14]$. Likewise the respective laboratory tests often fail to identify candida infection in symptomatic individuals $[3,15]$. This is partly because the current laboratory tests are not capable of discriminating between asymptomatic carriers and symptomatic candidiasis and that a good proportion of RVVC is due to nonalbicans Candida, the most common being C. glabrata, which is 
not easily identifiable on microscopy as it does not form hyphae or pseudohyphae [3].

RVVC is often diagnosed and treated on the basis of clinical features, namely symptoms and signs, without confirmatory laboratory tests. Many women self-diagnose and treat with over-the-counter preparations [16]. Since vaginal infections are an extremely common reason for women to seek care from a clinician, VVC is often over-diagnosed or misdiagnosed, leading to inappropriate treatment especially in resource-constrained developing countries. The frequent episodes of vulvo-vaginal candidiasis in RVVC, whose intensity may vary from one episode, or woman to another, lead to significant physical, psychological and social morbidity, as well as marked negative impact on the woman's sexual functioning $[3,5]$.

This paper reviews the pathogenesis, risk factors, diagnosis and management of RVVC with the aim of raising awareness among health care providers in the SSA region. It highlights the challenges in diagnosing and managing RVVC in a developing country context and proposes possible strategies to address them.

\section{Pathogenesis}

The pathogenesis of RVVC remains unresolved to date. Candida the causative organism is a commensal of the human vagina and gut [3], can be isolated from the vaginal tract in $20-30 \%$ of healthy, asymptomatic, non-pregnant women at any single point in time and in about $70 \%$ of women if followed longitudinally over a one year period $[17,18]$. C. albicans is the most common yeast in both symptomatic and asymptomatic carriers accounting for $80-90 \%$ $[19,20]$. Up to $20 \%$ are due to non-albicans, C. glabrata being the commonest of them all. Others include C. tropicalis, $C$. krusei, $C$. parapsilosis $[3,21]$. Studies have reported an increased prevalence of non-albicans Candida in RVVC over time [22,23], and studies from developing countries in particular have reported much higher prevalence of non-albicans Candida than the developed. A study in Nigeria by Okungbowa et al. [24] found that non-albicans Candida made up to $80 \%$ with C. glabrata accounting for $34 \%$ [24], while Ahmad et al. [25] in India reported that non-albicans made up $53 \%$ of which $37 \%$ was due to C. glabrata [25].

Local host immune response is crucial in the pathogenesis and host-pathogen interaction in genital candidiasis [26]. Host defense against Candida infection depends on intact mucosal and skin barriers, and adequate recognition of the fungus that subsequently triggers protective innate and adaptive antifungal defense mechanisms [27]. The state of commensalism is said to be temporarily disturbed when Candida causes genital candidiasis (VVC) while in RVVC this balance may be more permanently disturbed. It is still not clear though what causes either this temporary or permanent disturbance! It's been suggested that VVC is associated with signals that promote a non-protective inflammatory leucocyte response leading to the clinical symptoms $[1,28]$. Alteration of the vaginal ecosystem in certain conditions, which have been identified as risk factors for VVC and RVVC, such as sexual intercourse, use of antibiotics and female hygienic products [29], may also contribute to development of genital candidiasis.
The source of initial Candida involved in vaginal colonization and VVC is thought to be the intestine $[8,14]$. Recurrent episodes are thought to result from a vaginal relapse following an incomplete clearance of the yeast during a previous episode or vaginal re-infection during sexual intercourse from an intestinal reservoir or the partner's genitalia $[3,4,30]$. Of these two theories, a vaginal relapse is considered the more plausible because of the short intervals between the episodes as well as the finding that the same Candida species is responsible for the initial and subsequent episodes in the same individual $[14,30]$. The role of the intestinal reservoir in RVVC has been discounted because attempts to eradicate yeast from the gut have not significantly reduced symptomatic vaginal recurrences [31]. There have been suggestions of possible sexual transmission of Candida in RVVC as male partners of women with RVVC are four times more likely to have asymptomatic colonization of their genitalia with Candida than those of uninfected women [32]. However there is currently no evidence supporting sexual transmission as treatment of male partners does not seem to influence either cure or rate of recurrences [32].

\section{Risk Factors}

It's been suggested that women with RVVC are a separate population of otherwise healthy individuals who are distinct from those who experience sporadic or acute VVC. The principal predisposing factors for VVC are the following:

\section{Diabetes mellitus}

Vaginal colonization with candida is reportedly more frequent in diabetes than non-diabetic women, those with diabetes mellitus type- 2 being more prone to vaginal colonization with non-albicans Candida especially C. glabrata [33]. Uncontrolled diabetes mellitus predisposes to symptomatic vaginitis [34].

\section{Immunosuppression}

HIV infection is considered one of the risk factors for the development of symptomatic Candida infection. Most studies show a higher prevalence of vaginal candidiasis with a higher recurrence in HIV-infected women than uninfected women $[35,36]$. In a nested control analysis from a prospective study of 1404 women (716 HIV+ve and 688HIV-ve) in Kwazulu Natal South Africa, Sebitloane et al. [37] showed higher risk among the HIV infected than uninfected $(39.2 \%$ vs $30.0 \% \mathrm{RR}=1.31$ (1.08 1.59) $\mathrm{p}$ value $=0.006$ ) [37]. Oliviera et al. [38] found a two-fold increase in the risk among HIV+ve compared to HIV-ve women in Brazil [38]. Some studies have shown that increased rates of colonisation with Candida and symptomatic candidiasis are associated with decreased $\mathrm{CD} 4^{+}$cell count especially below 200 cells $/ \mathrm{mm}^{3}[36,39]$. HIV+ve women have been shown to have increased rates of colonization with non-albicans Candida more than HIV-ve women $[36,40]$. Ohmit et al. [41] suggested that mucosal candidiasis in HIV-seropositive women is a consequence of multiple interacting factors [41]. Use of corticosteroids, which may suppress ones immune response, has been reported to increase the risk of symptomatic yeast infection [42,43]. It is worth noting though that majority of women with RVVC are immunocompetent [44]. 


\section{Contraception}

This remains controversial and unresolved. Whereas highoestrogen contraceptives have been shown to increase the risk of genital candidiasis, $[45,46]$, similar effects have also been shown with low-oestrogen contraceptives [47]. Studies have reported an increase in colonization of the vagina in women using the IUCD's, contraceptive sponges, diaphragms and condoms, with or without spermicides [48]. However a study involving sexually active college students failed to show increased prevalence of symptomatic candidiasis among those using oral pills, diaphragms, condoms, or spermicides [5].

\section{Pregnancy}

The associated high concentration of reproductive hormones especially oestrogen in pregnancy increases the glycogen content in the vaginal epithelial cells, which increases the risk of colonization and symptomatic candidiasis $[49,50]$. A study by Glover \& Larsen [51] among pregnant women showed that vaginal colonization with Candida was a risk factor for subsequent symptomatic candidiasis [51]. RVVC is more common in pregnancy as well as decreased response to antifungal therapy compared to non-pregnant women [52].

\section{Antibiotic therapy}

This is an area that has elicited a lot of interest and concerns, cause of the widespread use of antibiotics among women of reproductive years for various ailments. Some studies have shown that VVC frequently follows antibiotic use [19,53,54]. Antibiotics eliminate the protective bacterial flora in the vagina, i.e. lactobacillus, thus allowing overgrowth of yeast [55]. It's been reported that $28-33 \%$ of women put on antibiotic therapy develop symptomatic genital candidiasis $[54,56]$. In a recent study among non-pregnant women receiving antibiotics for non-gynaecological conditions, $\mathrm{Xu}$ et al. [57] observed that short courses of oral antibiotics seem to increase the prevalence of asymptomatic vaginal Candida colonization and incidence of symptomatic VVC [57]. Their sample size was very small though. Studies have shown that alteration of or abnormal vaginal bacterial flora predispose to RVVC only in the presence of antibiotic use $[58,59]$. It is worth noting thought that the majority of women who receive antibiotics do not develop genital candidiasis and majority of women with genital candidiasis have not used antibiotics in the immediate past. Glover et al. [60] did not show an association between antibiotic use and VVC or RVVC [60]. Pirotta et al. [54] contend that those who develop genital candidiasis following antibiotic use are already colonized in their vagina by Candida [54]. While that may be true, it does not explain though how antibiotics transform the Candida from a commensal to a pathogen! Their suggestion is not supported by Glover \& Larsen [51] who in their study involving a cohort of pregnant women noted that while vaginal colonization is a risk factor for subsequent symptomatic genital candidiasis, antibiotic therapy, even intense therapy thereof, is not associated with an increased risk of developing symptoms [51].

\section{Sexual and behavioural factors}

Female genital hygiene habits and practices such as douching, use of deodorants, sprays and medicated soaps on/in the genitalia have been reported to increase the risk of RVVC [61,62]. Likewise wearing of tight-fitting clothes, non-cotton underwears, panty liners and hoses have been reported to increase local genital temperature, humidity and moisture, thus increasing the risk of genital candidiasis $[52,62]$. Local hypersensitivity or allergic reaction triggered by feminine hygienic practices may predispose some women to colonization with Candida or symptomatic infections [63].

The role of sexual activity per se and various sexual practices in the pathogenesis of genital candidiasis has attracted a lot of interest over the last three decades or so. Calderone et al. [64] opined that the role of sexual behavior in RVVC is underestimated [64]. The possibility of sexual transmission of Candida during penile-vaginal intercourse has been based on the fact that male partners of infected women are four times more likely to be colonized by Candida on their genitalia than those of uninfected women [65] and $20 \%$ of male partners of women with RVVC have Candida on their penises [66]. Of course the question would be what came first, i.e. what caused the other! Sexual intercourse alone has not been shown to alter vaginal Candida colonization, but certain practices may be of importance for both primary transmission of Candida and recurrence of symptomatic episodes (RVVC) [65]. Bailey et al. [67] observed an increased risk amongst women who have sex with women (WSW), which rose with the number of partners [67]. However, in a more recent study, Muznyl et al. [68] did not find evidence supporting sexual transmission of genital Candida between women (WSW) [68]. The few studies that have focused on specific sexual practices among women with RVVC have found positive association with early sexual debut, [69], casual sex partners in the preceding month [69], new sex partner in the last six months [70], sex during menses [69], receptive oral and anal intercourse [61,71,72] and frequency of vaginal intercourse [5]. Reed et al. [65] in their study on sexual behavior as a risk factor for RVVC found that female masturbation using saliva and cunnilingus from their partners and male masturbation with saliva increased the risk of genital candidiasis [65].

\section{Genetic factors}

Studies have suggested genetic predisposition to RVVC $[73,74]$. Blood group ABO Lewis non-secretor phenotype has been shown to be associated with increased vaginal colonization with Candida and symptomatic candidiasis [22].

\section{Dietary factors}

There are suggestions that diets rich in sugar content may increase the risk of genital candidiasis $[75,76]$. Rylander et al. [72] found an association between consumption of sweets and a positive culture of Candida [72]. Patel et al. [52] noted that consumption of cranberry was associated with a $\geq 2$ risk of RVVC [52]. Donders et al. [77] opined that diets rich in refined sugar may increase the risk of genital candidiasis [77]. However other studies did not find evidence to support the role of sugar consumption in genital candidiasis [78]. While deficiencies of minerals such as magnesium, zinc, calcium and iron have been associated with genital candidiasis in some studies, the evidence thereto is considered insufficient [79]. 


\section{Immunological factors}

Despite previous indications that RVVC was associated with systemic immune deficit [80], patients with RVVC are systemically immunocompetent, and that the immune deficit is local [44], i.e. genital. Studies on mouse models and humans highlight the immunopathological response as a crucial element of vaginal candidiasis pathogenesis [81]. It is thought that women with RVVC suffer relapsing genital candidiasis due to a change in the normal host defense mechanisms at the vaginal mucosal level. Mucocutaneous candidiasis is associated with T-cell impairment [82] and women with RVVC display a decrease in delayedhypersensitivity to C. albicans antigens but react normally to other antigens [83].

There is a strong association between atopy and RVVC [84], and a few studies have shown an association between RVVC and allergy to C. albicans [85], allergic conditions such as rhinitis, asthma and other familial allergies $[84,86,87]$. Higher levels of vaginal anticandida IgA and IgG have been reported in women with RVVC than those without [86]. C. albicans can act as an allergen in some cases and it's been suggested that local hypersensitivity to the yeast can contribute to a prolongation and recurrence of genital candidiasis [84]. In support thereof a few studies have shown benefits from desensitization using Candida antigens [87], and clinical response has been observed in about $30 \%$ of women with RVVC treated with leukotriene receptor antagonist Zafirlukast [88].

\section{Microbial factors}

RVVC is more often due to non-albicans Candida such as $C$. glabrata which is less susceptible to the azole antifungal agents [89]. Chong et al. [90] in their study in Malaysia showed that $C$. albicans that cause RVVC are less similar to each other than the strains causing sporadic VVC, thus suggesting that the former may represent more virulent sub-types [90]. Soll et al. [91] reported that although the genotype remains the same there is phenotype switching of C. albicans in RVVC [91] and Schroppel et al. [92] observed yeast genetic instability with repeated courses of antifungal treatments [92]. The genetic polymorphic nature of the organisms is considered a major factor in its virulence [93]. The fungistatic mode of action of the azole compounds used to treat VVC and RVVC contributes to fungal recalcitrance to clearance [94], hence the vaginal relapses. There have been concerns that the repeated treatment might induce drug resistance, as well as shift the spectrum of the causative Candida spp increasing the chances of non-albicans spp [95,96,97]. Azole resistance has been considered a possible factor in RVVC. Merchaim et al. [98] reported 25 cases of fluconazole resistant C. albicans [98]. However other studies have not shown significant drug resistance [15], and therefore it is not considered an issue in RVVC [14,99].

\section{Others}

Woman's age ( $<45$ years) and history of VVC have been shown to be strong determinants of a subsequent episode i.e. RVVC $[31,52]$. Vermitsky et al. [100] reported an increase in percentages of non-albicans Candida with increasing age of the woman [100]. Women with RVVC have been shown to be unable to tolerate even small number of Candida compared to healthy women [101].
Mixed infections with BV and VVC are not uncommon and a significant number of women with $\mathrm{BV}$ also have yeast residing in the vaginal ecosystem, which can either lead to failure of symptom resolution from therapy targeted at one infection or development of VVC from exposure to antibiotics. Among women diagnosed with bacterial vaginosis (BV), 33.1\% were colonized with yeast. This high prevalence of infection/colonization likely predisposes these women to symptomatic VVC after treatment for BV, leading to repeat visits to healthcare providers and higher healthcare costs in general [102].

\section{Diagnosis}

Recurrent vulvovaginal candidiasis (RVVC) is often misdiagnosed or over diagnosed, as the diagnosis is based on clinical features - symptoms and signs, which are neither specific nor sensitive. The related symptoms include itching, soreness, vaginal discharge, vulvar swelling, superficial dyspareunia and external dysuria $[3,13,103,104]$. Of these, pruritus and discharge are the most common complaints [15], and vulvar pruritus and soreness are the only symptoms predictive of a positive yeast culture [14]. The vaginal discharge varies in amount and consistency from watery to homogenously thick - what is referred to as "cottage-cheese like or curd-like and does not have an offensive smell $[19,79]$. Symptoms may sometimes be aggravated by sexual intercourse, e.g. pruritus [105-107]. The clinical signs include vulvar erythema, fissuring, vulvar swelling (oedema), excoriation, satellite lesions and whitish discharge. The cervix uteri often looks normal [3,13,96,104].

More than $50 \%$ of women with symptoms and signs suggestive of genital candidiasis self-reporting may have other conditions $[16,108]$ and since none of the clinical features is pathognomonic for genital candidiasis, corroborative laboratory evidence in necessary. These include:

a) $\mathrm{pH}$ test of the vaginal fluid/discharge from the vaginal walls. This should be $4.0-4.5$. If it is $>4.7$ other infections should be considered $[3,109]$, such as bacterial vaginosis, trichomoniasis or mixed infections. This simple test can promptly exclude VVC or two of the most common causes of vaginitis.

b) Microscopy: A wet mount or saline preparation can be done routinely to not only identify yeast cells and mycelia, but also exclude other conditions such as bacterial vaginosis (clue cells) and trichomoniasis (trichomonads). Gram stain of vaginal discharge suspended in or mixed with $10 \% \mathrm{KOH}$ is said to be more sensitive in identifying yeast cells or hyphae with a $65-85 \%$ sensitivity $[3,109]$.

c) Culture: Recovery of yeast in fungal cultures using Sabourad's Dextrose Agar (SDA) remains the gold standard for diagnosing genital candidiasis $[3,19,103,104]$. Other media used include Nickerson's or Microstix Candida, which are considered similar in performance to SDA $[3,96]$. Culture is useful and indicated in patients who either:

A. Have symptom and signs suggestive of genital candidiasis, have a normal $\mathrm{pH}(4.0-4.5)$, but have a negative microscopy. This is critical as $\geq 50 \%$ of patients with culture positive symptomatic genital candidiasis have negative microscopy. 
B. Have positive microscopy but fail to respond to the standard therapy i.e. with azole antifungals $[94,110,111]$.

These media do not discriminate among the Candida spp. Thus because of the relatively high possibility of non-albicans Candida in RVVC, it is at times necessary to use tests which distinguish them. Chromogenic Agar is considered a convenient and reliable means to detect Candida and differentiate between $C$. albicans and non-albicans spp. [104]. It has been suggested that it could be used in place of SDA for its advantages which include high yeast recovery rates, differentiation of different Candida spp. and identification of polyfungal populations even though it is more costly $[98,104]$.

F) Other tests: Susceptibility tests are considered most helpful in patients previously treated with an azole when there is a possibility of antifungal resistance. These are however not considered routine procedures and are not easily available. Furthermore identification of the species is highly predictive of likely susceptibility and can be used as a guide for therapy [8]

Rapid PCR-based assays have been used to detect $C$. species causing RVVC $[112,113]$. They are said to have high sensitivity and specificity and a shorter turn-around time in comparison to current microscopy and culture techniques. However they are not easily available as a diagnostic test and not considered clinically useful [114]. Pap smear, though specific is insensitive. It is only positive in $25 \%$ of patients with culture-positive symptomatic genital candidiasis [3]. Antigen detection and serologic tests are not reliable and not clinically useful [3].

\section{Treatment}

The aim of treating patients with RVVC include:-

I. Elimination of potentially reversible risk factors or controlling those not reversible

II. Symptomatic relief as promptly as possible

III. Clearance of the yeast from the genitalia

IV. Prevention of repeat episodes

Once and if potential risk factors are identified, the patient and her sexual partner or spouse should be counselled appropriately and in an empathetic manner, supported to eliminate or control them. Some of the general measures include avoiding tight-fitting synthetic clothing and local irritants e.g. perfumed products [52].The vaginal environment can be altered by changing the contraception to depot-medroxyprogesterone acetate [50].

There are various treatment options for RVVC. The challenge has been to get a drug that can be administered safely, is acceptable, and well tolerated by the patients, thus improving compliance. Treatment of RVVC requires well-tolerated antifungal agents and better understanding of its pathogenesis as well as natural history. There is currently no gold standard for the treatment of RVVC [8]. The principle of therapy involves an induction regimen to ensure clinical remission, followed immediately by a maintenance regimen $[3,115,116]$.
A) Induction therapy

i. Fluconazole $-150 \mathrm{mg}$ orally in three doses given every 72 hours[115,117], or

ii. Clotrimazole $100 \mathrm{mg}$ vaginally daily for 7 days $[3,8,115]$

1. For azole resistant Candida spp,

B) Flucytosine $17 \%$ cream either alone or in combination with Amphotericin B 3\% cream daily for 14 days, or

C) Boric acid gelatin capsule $-600 \mathrm{mg}$ vaginally daily for 14 days $[13,94]$.

\section{D) Maintenance therapy:}

i. Fluconazole $150 \mathrm{mg}$ orally weekly for 6 months [115], or

ii. Clotrimazole cream $200 \mathrm{mg}$ twice weekly or $500 \mathrm{mg}$ weekly for 6 months, or

iii. Itraconazole $400 \mathrm{mg}$ monthly or 100 weekly for 6 months $[3,8,111]$.

iv. For non-albicans or azole resistant Candida albicans spp

v. Boric acid $600 \mathrm{mg}$ vaginally once or twice weekly for 6 months, or

vi. Flucytosine $17 \%$ cream vaginally either alone or in combination with 3\% Amphotericin cream daily for 6 months $[3,13,111]$, or

vii. Gentian Violet 1\% weekly for 4-6 months in combination with topical nystatin or Boric acid [13]

viii. In case of recurrence after maintenance regimen each subsequent episode should be treated independently as an acute or sporadic VVC. If recurrence is established induction and maintenance regimens should be instituted.

ix. For pregnant women, avoid oral treatment and use topical azoles and for longer courses [118].

\section{E) Alternative treatment:}

a) Use of probiotics - There are anecdotal reports of benefits. Their mode of action is thought to be modulation of the inflammatory process rather than competitive effect with the yeast [119]. In a recent study Vicariotto et al. [120] reported that probiotics reduce recurrences [120].

b) Zafirlukast $20 \mathrm{mg}$ twice daily for 6 months [88] may be considered for those with atopy [84].

c) Cetirizine $10 \mathrm{mg}$ orally daily for 6 months [84].

d) Immunotherapeutic approaches that have been proposed as adjuvant therapy in Candida infections [121].

\section{Discussion}

Abnormal vaginal discharge and vulvar pruritus are two very common complaints for which women present to health facilities all over the globe, and genital candidiasis is among the 
most common causes thereof. It is considered the second most common cause after bacterial vaginosis accounting for up to $40 \%$ in primary health care settings [15]. It is prevalent during the individuals' highest sexual activity and reproductive years i.e. 15 to 40 years. While for the majority it occurs in sporadic form i.e. acute VVC, in a minority ( $<10 \%$ of those who suffer one episode) it is recurrent, i.e. they experience at least 4 symptomatic episodes in a year $[3,79,122]$.

Whereas it is said to be very common the actual magnitude of VVC and RVVC is unknown. Rathod et al. [123] expressed doubts on the often quoted figures in various publications, and contended that these are higher than the true magnitude of the problem [123]. Recent reports though indicate that the incidence of genital candidiasis is increasing [124]. Cognisant of global increases in some of the key risk factors thereof, such as diabetes mellitus, antibiotic use, and changing individual life-styles and more liberal sexual behaviours and practices which may increase the risk thereto, this assertion may not be far-fetched. This is of particular concern for women in the developing countries such as those in SSA as their life-styles, among other factors are changing rapidly in tandem with globalization and expansion of access to the electronic and/or digital media. Indeed I see more patients with abnormal vaginal discharge now in both private clinic and public health institution than I did some 20 years ago!

The pathogenesis of RVVC remains controversial. Candida, the causative organism, which is part of the normal microbial flora of the lower genital tract in about $20-25 \%$ of healthy asymptomatic adult females, is the same organism responsible for symptomatic infection [31,75,102]. The unanswered question is how an organism that is a commensal transforms itself into a pathogen capable of causing such severe and recurring symptoms in the same site. The pathogenesis of RVVC is considered multifactorial with a number of factors acting synergistically to facilitate and enhance Candida overgrowth, leading to clinical symptoms. The primary pathology in genital candidiasis is inflammation of the lower genital tract - vulva and vagina, secondary to an overgrowth or abnormal growth of Candida. This is thought to be caused more by host factors rather than a more virulent strain or re-introduction of the organism into the genital tract [2], and available evidence suggest an immunological basis for the pathogenesis of genital candidiasis $[2,3,125]$.

Hypothesized risk factors for VVC include pregnancy; a history of VVC; sexual practices, (in particular receptive oral sex); oral contraceptive or replacement therapy; diabetes mellitus and immunodeficiency states $[6,72,78,126]$. However, definitive evidence relating to each of these factors is limited $[7,78]$. Epidemiologic studies have failed to measure the true attack rate and have been unable to specifically identify characteristics of the at-risk subpopulation [7,57]. The variation may be due to diagnostic criteria, methodological or study population differences.

Of special interest and concern for the SSA and in particular the Eastern, Central and Southern Africa sub-regions, is the reported association between genital candidiasis and HIV/ AIDS, because of the comparatively high prevalence of the latter
$[37,39]$. HIV infection is involved in changes in the normal vaginal flora that favour the development of local infections, which in turn lead to increased local viral replication $[127,128]$. These increase sexual transmission of HIV [129]. Genital candidiasis is more frequently diagnosed and with greater persistence in HIV infected women than uninfected [36]. HIV/AIDS have been cited as major contributing factors to the increase in the incidence of fungal infections $[130,131]$. There is also higher diversity of nonalbicans Candida spp in HIV infected women [38]. Spinillo et al. [132] reported that these patients have higher frequency of $C$. glabrata and are more prone to recurrence than HIV-negative controls [132]. There is also higher diversity of non-albicans Candida spp [38]. The extensive use of prophylactic antifungal for opportunistic infections in HIV/AIDS may increase non-albicans spp in RVVC as well as resistance of $C$. albicans to the common azole compounds used $[36,40]$, thus complicating treatment thereof. There are also concerns that RVVC may increase the risk of HIV acquisition [133]. Rottigen et al. [134] reported a two-fold increase in the risk of HIV acquisition in women with genital candidiasis compared to the uninfected [134]. Apalata et al. [39] reported that genital candidiasis was associated with genital shedding of HIV ( $p=0.0002)$ [39]. This was supported by Wang et al. [135]. Simon et al. [136] opined that genital candidiasis may contribute to an increase in population level risk of HIV infection [136]. There are also concerns that use of topical azole for treatment of genital candidiasis may affect the integrity of the latex condom, thus increasing risk of HIV transmission! All these present serious challenges with treatment of RVVC as well as HIV/AIDS in countries with high incidence thereof, such as the developing countries of SSA. Could the foregoing therefore account at least in part for the fact that women in SSA are more susceptible to HIV infection and could it also explain the relatively higher prevalence of HIV/AIDS in young sexually active women? If that is true, there is an urgent need to include in the preventive strategies screening and treatment of genital candidiasis! Indeed Goel et al. [137] in their study in India noted that the prevalence of reproductive tract infections (RTI) including candidiasis in HIV-seropositive women was high enough to warrant routine gynaecological evaluation and RTI screening in these patients [137]. Occurrence and recurrence of opportunistic infections in HIV positive individuals is a challenge faced by clinicians worldwide. Although the majority of cases of recurrent vulvovaginal candidiasis (VVC) develop without predisposing factors, it is a common problem in women with HIV infection. Considering all the above and as one of the studies has effectively demonstrated that non albicans strains (which are more resistant) do develop as a result of VVC prophylaxis with fluconazole; the question therefore is whether routine prophylaxis should be given at all to HIV positive women for VVC on the basis of the present evidence or whether more trials are required which include and investigate all the above aspects before a judgment can be made as regards routine prophylaxis of VVC in HIV positive. Azoles are the mainstay of the treatment of candidiasis in any form and development of resistance to these drugs would not be desirable especially since VVC rarely if ever leads to systemic candidiasis or other such life threatening situation which makes waiting until the VVC appears before starting treatment an alternative to prophylaxis. 
The theory that recurrence may be due to reinfection of the woman by her male sexual partner has been suggested repeatedly with some data indicating that sexual transmission does occur $[65,66,69]$. Candida spp may be harboured in the male GIT, semen, oral cavity and urine [78,138], and male colonization is often associated with vaginal colonization often with the same strain of Candida [66,139]. Studies have indicated that oral sex performed by the male partner (cunnilingus) is associated with both incident and recurrent candidiasis [65,69]. Bailey et al. [67] reported an increased risk of genital candidiasis among women who have sex with women (WSW), which rose with number of partners [67]. Although they concluded that this possible sexual transmission whatever WSW practice, often include oral sex, as well as other sexual practices/activities. They however did not report on the actual practice these women did with each other! Indeed Reed [78] had suggested that it is the sexual behaviours rather the presence of Candida spp at various body locations of the male partners that are associated with recurrences of genital candidiasis [78]. Receptive oral sex has become fashionable and part of many young partners' sexual repertoire even in the developing world in lieu of penetrative sexual intercourse or part of the foreplay. This has the potential of increasing prevalence of VVC and RVVC in young sexually active women! The role of sexual transmission has yet to be defined. Clarification of this controversy could avoid unnecessary treatment of sexual partners, thus reducing costs, side effects and conflict among couples.

Although the widespread use of antibiotics has been suggested as one of the major factors contributing to the rising incidence of genital candidiasis $[45,126]$, the supportive evidence has been limited. [57]. Accordingly, existing data on the risk of developing antibiotic-associated VVC are conflicting [57,78,126]; For example, some case-control studies [6] found no evidence of an association between antibiotic agents and symptomatic VCC, whereas others reached the opposite conclusion. Results from a prospective study of 250 pregnant women concluded that extensive antibiotic use posed little risk for the development of yeast infection [51]. Antibiotic use is known to increase colonisation with yeast. The precise relationship between yeast colonization and symptomatic yeast vaginitis is not entirely clear. However yeast colonization is considered a necessary precursor for subsequent symptomatic VVC [7]. Bluestein et al. [56] reported a 35\% Candida colonization at baseline that increased to $50 \%$ after 10 days of antibiotic therapy [56]. Pirotta et al. [140] reported increased Candida colonization from $21 \%$ at baseline to $37 \% 2$ weeks after antibiotics use and $23 \%$ of women developed symptomatic VVC after antibiotics [140]. Critical factors determining individual susceptibility to antibiotic-associated VVC remain to be determined.

Diagnosis of genital candidiasis including RVVC is usually made on the basis of clinical signs and symptoms [140] without even the benefit of physical examination and/or laboratory tests in most of our clinical settings. Some patients even self-medicate with over-the-counter prescriptions. Some of the reasons for this include financial constraints, lack of diagnostic facilities and awareness of the value of confirmatory laboratory tests. However even when they are performed, they are not conclusive and do not necessarily confirm the diagnosis. This may be due to the fact that about $20-25 \%$ of healthy women are colonized in their vagina by Candida, the clinical features are not pathognomonic of genital candidiasis and the presence of non-albicans spp such as $C$. glabrata which is not easily recognized on microscopy as it does not form hyphae or pseudohyphae. In a large study involving women attending an STD clinic, Eckert et al. [109] found that only $28 \%$ of women with symptoms suggestive of candidiasis $(n=545)$ were Candida culture positive [109]. This is indeed a big challenge and of major concerns for the developing countries, as laboratory diagnosis is considered essential in RVVC [100], but is not always available and when it is done and treatment based on the results thereto, one can't be sure that the patient in question actually had genital candidiasis and not other conditions!

There is currently no gold standard treatment of RVVC. The recommended regimens including induction therapy at times up to two weeks followed by maintenance therapy for up to six months, which have been supported by randomized clinical trials [115], have numerous challenges. The repeated treatments may increase the likelihood of drug resistance as well as shift the spectrum of causative Candida spp [76,89,95-97]. The same has been said with regards to widespread use of azole compounds especially when the diagnosis is not confirmed [14,142]. MacNeill et al. [143] suggested that the increase in the number of women with RVVC can be attributable to over-the-counter antifungal prescriptions [143]. The high prevalence of non-albicans Candida spp in RVVC which has been shown to be more common in the developing countries is a worrying situation as $C$. glabrata has been shown to have high minimum inhibitory concentration (MIC) to azole, and C. krusei is intrinsically resistant to fluconazole $[131,144]$. Richter et al. [89] reported that $67 \%$ of C. glabrata from vaginal isolates were not susceptible to azole compounds [89]. Though boric acid is very effective in their treatment its efficacy ends with cessation of treatment [89]. The long duration of treatment $\geq 6$ months has the potential of impacting on compliance, which may worsen recurrences. It may also lead to colonisation with less susceptible Candida spp or development of resistance among usually susceptible Candida albicans strains and ultimately to refractory candidiasis $[11,145]$. The fact that there is no cure even after such a prolonged treatment course, with 60$70 \%$ having a recurrent episode within two months $[94,116]$, may lead to frustration among the patients who may not accept and/or use antifungals for the next episode. Martinez [146] reported that the frequent and/or long-term antifungal therapy may predispose to bacterial vaginosis [146], and Patel et al. [52] observed that young women with bacterial vaginosis may have an increased risk of genital candidiasis [52].

There have been efforts to identify preventive strategies for RVVC, which have not been very successful basically because on non-resolution of the pathogenesis, the risk factors and protective factors. Contrary to the commonly posited hypothesis that vaginal lactobacillus colonisation has a protective effect, McClelland [102] found that such colonization was in fact associated with nearly four-fold increase in the likelihood of symptomatic genital candidiasis [102]. Pirotta et al. [140] reported that neither oral nor vaginal lactobacillus administration prevented genital candidiasis following antibiotic use [54]. Falagas et al. [147] reviewed publications on use probiotics for prevention of RVVC, and noted that the available evidence for the use of probiotics for 
prevention of recurrent VVC is limited. Most of the relevant clinical trials had methodological problems such as small sample sizes, no control groups (placebo) and included women without confirmed recurrent VVC. They contended though that empirical use of probiotics may be considered in women with RVVC, especially for those who have adverse effects from or contraindications for the use of antifungal agents, since adverse effects of probiotics are very rare [147]. In a more recent study Vicariotto et al. [120] reported that probiotics reduce recurrences [120]. However their sample size was also very small.

A few studies have shown some benefits from desensitization programmes using Candida antigens [54,87]. It is not clear how big the magnitude of benefit and who is best suited for that. New insights into the mechanisms of the anti-Candida host response have contributed to the design of novel immunotherapeutic approaches that have been proposed as adjuvant therapy in Candida infections [121]. Immunotherapy is considered a potential new frontier in the management of candidiasis. The need to personalize treatment of RVVC has been advocated for [148], which has been shown to improve compliance and efficacy thereof.

\section{Conclusions and Recommendations}

RVVC remains an intractable problem for clinicians and patients alike inspite of major therapeutic advances globally. RVVC is a highly troublesome and emotionally traumatic condition for women. It is a source of considerable physical discomfort. It affects the woman's quality of life and may impact negatively on her sexual life as well. The latter may be due to the associated dyspareunia, fear of triggering a crisis or infecting ones partner. Some may avoid sexual intimacy with their partners as the symptomatic episodes may be associated with recent and/ or frequency of sexual intercourse or particular sexual practice. The woman's social and professional lives may also be seriously affected by the recurring symptoms for which there is no cure. Others may feel embarrassed and therefore psychologically affected because genital candidiasis is still regarded as a sexually transmitted infection, by both health providers and the general public despite evidence to the contrary! The associated costs of medical visits are high.

All health care providers need to be aware of the pathogenesis, potential risk factors, the value of confirmatory laboratory tests and which ones, as well as appropriate management for RVVC. They should also take cognizance of the challenges thereto. Of critical importance especially for primary care health workers are women who may present with dysuria as some of these may be due to genital candidiasis and routine antibiotic prescription as is often the practice may only serve to worsen the symptoms. Cognisant of the magnitude of the problem and associated effects such as cost, impact on the woman's life and the potential of increase as outlined above, there is need for locally relevant research studies to better understand genital candidiasis in the local context. They may include predisposing factors, preventive strategies, drugs and drug regimens for RVVC treatment especially in HIV infected women. There is also need for national or regional guidelines for its management.

\section{References}

1. Barousse MM, Espinosa T, Dunlap K, Fidel PL (2005) Vaginal epithelial cell anti-Candida albicans activity is associated with protection against symptomatic vaginal candidiasis. Infect Immun 73(11): 7765-7767.

2. Fidel PL, Sobel JD (1996) Immunopathogenesis of recurrent vulvovaginal candidiasis. Clin Microbiol Rev 9(3): 335-348.

3. Sobel JD (2007) Vulvovaginal candidosis. Lancet 369(9577): 19611971.

4. Magliani W, Conti S, Cassone A, De Bernardis F, Polonelli L (2002) New immunotherapic strategies to control vaginal Candidiasis. Trends Mol Med 8(3): 121-126.

5. Foxman B (1990) The epidemiology of vulvovaginal candidiasis: risk factors. Am J Public Health 80(3): 329-331.

6. Geiger AM, Foxman B (1996) Risk factors for vulvovaginal candidiasis: a case-control study among university students. Epidemiology 7(2): 182-187.

7. Sobel JD, Faro S, Force RW, Foxman B, Ledger WJ, et al. (1998) Vulvovaginal candidiasis: epidemiologic, diagnostic, and therapeutic considerations. Am J Obstet Gynecol 178(2): 203-211.

8. Pappas PG, Kauffman CA, Andes D, Benjamin DK, Calandra TF, et al. (2009) Clinical practices guidelines for the management of candidiasis: 2009 update by the Infectious Diseases Society of America. Clin Infect Dis 48(5): 503-535.

9. Sheary B, Dayan L (2005) Recurrent vulvovaginal candidiasis. Aust Fam Physician 4(3): 147-150.

10. Ringdahl EN (2000) Top of Form Treatment of Recurrent Vulvovaginal Candidiasis. Am Fam Physician 61(11): 3306-3312.

11. Sobel JD, Kapernick PS, Zervos M, Reed BD, Hooton T, et al. (2001) Treatment of complicated Candida vaginitis: comparison of single and sequential doses of fluconazole. Am J Obstet Gynecol 185(2): 363-369.

12. Fidel PL (2004) History and new insights into hosts defense against vaginal candidiasis. Trends Microbiol 12: 220-227.

13. Edwards L (2004) The diagnosis and treatment of infectious vaginitis. Dermatol Ther 17(1): 102-110.

14. El-Din SS, Reynolds MT, Ashbee HR, Barton RC, Evans EGV (2001) An investigation into the pathogenesis of vulvo-vaginal candidosis. Sex Transm Inf 77: 179-183.

15. Anderson MR, Klink K, Cohrssen A (2004) Evaluation of vaginal complaints. JAMA 291(11): 1368-1379.

16. Ferris DG, Dekle C, Litaker MS (1996) Women's use of over-thecounter antifungal medications for gynecologic symptoms. J Fam Pract 42(6): 595-600.

17. Bauters TG, Dhont MA, Temmerman MI, Nelis H (2002) Prevalence of vulvovaginal candidiasis and susceptibility to fluconazole in women. Am J Obstet Gyneco 187(3): 569-574.

18. Beigi RH, Meyn LA, Moore DM, Krohn MA, Hillier SL (2004) Vaginal yeast colonization in non-pregnant women: A longitudinal study. Obstet Gynecol 104(5 pt 1): 926-930.

19. Guzel AB, Ilkit M, Akar T, Burgut R, Demir SC (2011) Evaluation of risk factors in patients with vulvovaginal candidiasis and the value 
of chromID Candida agar versus CHROMagar Candida for recovery and presumptive identification of vaginal yeast species. Med Mycol 49(1): 16-25.

20. Singh S, Sobel JD, Bhargava P, Boikov D, Vazquez JA (2002) Vaginitis due to Candida krusei: epidemiology, clinical aspects, and therapy. Clin Infect Dis 35: 1066-1070.

21. Holland J, Young ML, Lee O, Chen CA (2003) Vulvovaginal carriage of yeasts other than Candida albicans. Sex Trans Infect 79: 249-250.

22. Chaim W, Foxman B, Sobel JD (1997) Association of recurrent vaginal candidiasis and secretory $\mathrm{ABO}$ and Lewis phenotype. Infect Dis 176(3): 828-830.

23. Spinillo A, Capuzzo E, Gulminetti R, Marone P, Colonna L, et al. (1997) Prevalence of and risk factors for fungal vaginitis caused by non-albicans species. Am J Obstet Gynecol 176(1 Pt 1): 138-141.

24. Okungbowa FI, Isikhuemhen OS, Dede AP (2003) The distribution frequency of Candida species in the genitourinary tract among symptomatic individuals in Nigerian cities. Rev Iberoam Micol 20(2): 60-63.

25. Ahmad A, Khan AU (2009) Prevalence of Candida species and potential risk factors for vulvovaginal candidiasis in Aligarh, India. Eur J Obstet Gynecol Reprod Biol 144(1): 68-71.

26. Richardson M, Rautemaa R (2009) How the host fights against Candida infections. Front Biosci (Landmark Ed) 14: 4363-4375.

27. Netea MG, Brown GD, Kullberg BJ, Gow NA (2008) An integrated model of the recognition of Candida albicans by the innate immune system. Nat Rev Microbiol 6(1): 67-78

28. Fidel PL, Barousse M, Espinosa T, Ficarra M, Sturtevant J, et al. (2004) An intravaginal live Candida challenge in humans leads to new hypotheses for the immunopathogenesis of vulvovaginal candidiasis. Infect Immun 72(5): 2939-2946.

29. Ramírez-Santos A, Pereiro JM, Toribio J (2008) Recurrent Vulvovaginitis: Diagnostic Assessment and Therapeutic Management. Actas Dermosifiliogr 99(3): 190-198.

30. Vazquez JA, Sobel JD, Demitriou R, Vaishampayan J, Lynch M, et al. (1994) Karyotyping of Candida albicans isolates obtained longitudinally in women with recurrent vulvovaginal candidiasis. J Infect Dis 170(6): 1566-1569.

31. Foxman B, Barlow R, D'Arcy H, Gillespie B, Sobel JD (2000) Candida vaginitis: self-reported incidence and associated costs. Sex Transm Dis 27(4): 230-235.

32. Shihadeh AS (2000) The value of treating the male partner in vaginal candidiasis. Saudi Med J 21(11): 1065-1067.

33. de Leon EM, Jacober SJ, Sobel JD, Foxman B (2002) Prevalence and risk factors for vaginal Candida colonization in women with type 1 and type 2 diabetes. BMC Infect Dis 2: 1 .

34. Goswami R, Dadhwal V, Tejaswi S, Datta K, Paul A, et al. (2000) Species-specific prevalence of vaginal candidiasis among patients with diabetes mellitus and its relation to their glycaemic status. J Infect 41(2): 162-166.

35. Ray A, Ray S, George AT, Swaminathan N (2011) Interventions for prevention and treatment of vulvovaginal candidiasis in women with HIV infection. Cochrane Database Syst Rev 10(8): CD008739.

36. Duerr A, Heilig CM, Meikle SF, Cu-Uvin S, Klein RS, et al.(2003) Incident and persistent vulvovaginal candidiasis among human immunodeficiency virus-infected women: risk factors and severity. Obstet Gynecol 101(3): 548-556.

37. Sebitloane HM, Moodley J, Esterhuizen TM (2011) Pathogenic lower genital tract organisms in HIV-infected and uninfected women, and their association with postpartum infectious morbidity. S Afr Med J 101(7): 466-469.

38. Oliveira PM, Mascarenhas RE, Lacroix C, Ferrer SR, Oliveira RPC, et al. (2011) Candida species isolated from the vaginal mucosa of HIVinfected women in Salvador, Bahia, Brazil. Braz J Infect Dis 15(3): 239-244.

39. Apalata T, Mbenza LB, Sturm AW, Carr WH, Moodley P (2014) Factors Associated with Symptomatic Vulvovaginal Candidiasis: A Study among Women Attending a Primary Healthcare Clinic in Kwazulu-Natal, South Africa. Ann Med Health Sci Res 4(3): 410416.

40. Fidel PL, Vazquez JA, Sobel JD (1999) Candida glabrata: review of epidemiology, pathogenesis, and clinical disease with comparison to C. albicans. Clin Microbiol Rev 12(1): 80-96.

41. Ohmit SE, Sobel JD, Schuman P, Duerr A, Mayer K, et al. (2003) Longitudinal study of mucosal Candida species colonization and candidiasis among human immunodeficiency virus (HIV)seropositive and at-risk HIV-seronegative Women. J Infect Dis 188(1): 118-127.

42. Knight L, Fletcher J (1971) Growth of Candida albicans in saliva: stimulation by glucose associated with antibiotics, corticosteroids, and diabetes mellitus. J Infect Dis 123(4): 371-377.

43. Schuman P, Sobel JD, Ohmit SE, Mayer KH, Carpenter CC, et al. (1998) Mucosal candidal colonization and candidiaisis in women with or at risk for human immunodeficiency virus infection. HIV Epidemiology Research Study (HERS) Group. Clin Infect Dis 27(5): 1161-1167.

44. Fidel PL (2007) History and update on host defense against vaginal candidiasis. Am J Reprod Immunol 57(1): 2-12

45. Ferrer J (2000) Vaginal candidosis: epidemiological and etiological factors. Intl J Gynecol Obstet 71(Suppl 1): S21-7.

46. Cetin M, Ocak S, Gungoren A, Hakverdi AU (2007) Distribution of Candida species in women with vulvovaginal symptoms and their association with different ages and contraceptive methods. Scand J Infect Dis 39(6-7): 584-588.

47. Barbone F, Austin H, Louv WC, Alexander WJ (1990) A follow-up study of methods of contraception, sexual activity, and rates of trichomoniasis, candidiasis, and bacterial vaginosis. Am J Obstet Gynecol 163(2): 510-514.

48. Demirezen S, Dirlik 00, Beksac MS (2005) The association of candida infection with intrauterine contraceptive device. Cent Eur J Public Health 13(1): 32-34.

49. Dennerstein GJ, Ellis DH (2001) Oestrogen, glycogen and vaginal candidiasis. Aust N Z J Obstet Gynaecol 41(3): 326-328.

50. Tarry W, Fisher M, Shen S, Mawhinney M (2005) Candida albicans: the estrogen target for vaginal colonization. J Surg Res 129(2): 278282 .

51. Glover DD, Larsen B (1998) Longitudinal investigation of Candida vaginitis in pregnancy: role of superimposed antibiotic use. Obstet Gynecol 91(1): 115-118. 
52. Patel DA, Gillespie B, Sobel JD, Leaman D, Nyirjesy P, et al. (2004) Risk factors for recurrent vulvovaginal candidiasis in women receiving maintenance antifungal therapy: results of a prospective cohort study. Am J Obstet Gynecol 190(3): 644-653.

53. Wilton L, Kollarova M, Heeley E, Shakir S (2003) Relative risk of vaginal candidiasis after use of antibiotics compared with antidepressant in women: postmarketing surveillance data in England. Drug Saf 26(8): 589-597.

54. Pirotta MV, Gunn JM, Chondros P (2003) "Not thrush again!" Women's experience of post-antibiotic vulvovaginitis. Med J Aust 179(1): 43-46.

55. Pultz NJ, Stiefel U, Ghannoum M, Helfand MS, Donskey CJ (2005) Effect of parenteral antibiotic administration on establishment of intestinal colonization by Candida glabrata in adult mice. Antimicrob Agents Chemother 49(1): 438-440.

56. Bluestein D, Rutledge C, Lumsden L (1991) Predicting the occurrence of antibiotic-induced candidal vaginitis (AICV). Fam Pract Res J 11(3): 319 -326.

57. Xu J, Schwartz K, Bartoces M, Monsur J, Severson RK, et al. (2008) Effect of Antibiotics on Vulvovaginal Candidiasis: A MetroNet Study. J Am Board Fam Med 21(4): 261-268.

58. Vitali B, Pugliese C, Biagi E, Candela M, Turroni S, et al. (2007) Dynamics of vaginal bacterial communities in women developing bacterial vaginosis, candidiasis, or no infection, analyzed by PCRdenaturing gradient gel electrophoresis and real-time PCR Appl Environ Microbiol 73(18): 5731-5741.

59. Zhou X, Westman R, Hickey R, Hansmann MA, Kennedy C, et al. (2009) Vaginalmicrobiota of women with frequent vulvovaginal candidiasis. Infect Immun 77(9): 4130-4135.

60. Glover DD, Larsen B (2003) Relationship of fungal vaginitis therapy to prior antibiotic exposure. Infect Dis Obstet Gynecol 11(3): 157160

61. Bradshaw CS, Morton AN, Garland SM, Morris MB, Moss LM, et al. (2005) Higher-risk behavioral practices associated with bacterial vaginosis compared with vaginal candidiasis. Obstet Gynecol 106(1): 105-114

62. Ekpenyong CE, Inyang-etoh EC, Ettebong EO, Akpan UP, Ibu JO, et al. (2012) Recurrent vulvovaginal candidosis among young women in south eastern Nigeria: the role of lifestyle and health-care practices. Int J STD AIDS 23(10): 704-709.

63. Bingham JS (1999) What to do with the patient with recurrent vulvovaginal candidiasis. Sex Transm Inf 75(4): 225-227.

64. Calderone RA, Fonzi WA (2001) Virulence factors of Candida albicans. Trends Microbiol 9(7): 327-335.

65. Reed BD, Zazove P, Pierson CL, Gorenflo DW, Horrocks J (2003) Candida transmission and sexual behaviors as risks for a repeat episode of Candida vulvovaginitis. Womens Health (Larchmt.) 12(10): 979-989.

66. Schmid J, Rotman M, Reed B, Pierson CL, Soll DR (1993) Genetic similarity of candida albicans strains from vaginitis patients and their partners. J Clin Microbiol 31(1): 39-46.

67. Bailey JV, Benato R, Owen C, Kavanagh J (2008) Vulvovagina candidiasis in women who have sex with women. Sex Transm Dis 35(6): 533-536
68. Muzny CA, Rivers CA, Parker CJ, Mena LA, Austin EL, et al. (2014) Lack of evidence for sexual transmission of genital Candida species among women who have sex with women: a mixed methods study. Sex Transm Infect 90(2): 165-170.

69. Hellberg D, Zdolsek B, Nilsson S, Mardh PA (1995) Sexual behavior of women with repeated episodes of Vulvovaginal candidiasis. Eur J Epidemiol 11(5): 575-579.

70. Spinillo A, Pizzoli G, Colonna L, Nicola S, De Seta F, et al. (1993) Epidemiologic characteristics of women with idiopathic recurrent Volvo vaginal candidiasis. Obstet Gynecol 81(5(Pt1)): 721-727.

71. Markos AR, Wade AA, Walzman M (1992) Oral sex and recurrent vulvo-vaginal candidiasis. Genitourin Med 68(1): 61-62.

72. Rylander E, Berglund A-L, Krassny C, Petrini B (2004) Vulvovaginal candida in a young sexually active population: prevalence and association with oro-genital sex and frequent pain at intercourse. Sex Transm Infect 80: 54-57.

73. Giraldo PC, Babula O, Goncalves AKS, Linhares IM, Amaral RL, et al (2007) Mannose-binding lectin gene polymorphism, vulvovaginal candidiasis, and bacterial vaginosis. Obstet Gynecol 109(5): 11231128.

74. Babula O, Lazdane G, Kroica J, Ledger WJ, Witkin SS (2003) Relation between recurrent vulvovaginal candidiasis, vaginal concentrations of mannose-binding lectin, and a mannose-binding lectin gene polymorphism in Latvian women. Clin Infect Dis 37(5): 733-737.

75. Akah PA, Nnamani CE, Nnamani PO (2010) Prevalence and treatment outcome of Vulvovaginal candidiasis in pregnancy in a rural community in Enugu State, Nigeria. Journal of Medicine and Medical Sciences 1(10): 447-452.

76. Mårdh PA, Rodrigues AG, Genç M, Novikova N, Martinez-deOliveira J, et al. (2002) Facts and myths on recurrent Vulvovagina candidosis-a review on epidemiology, clinical manifestations, diagnosis, pathogenesis and therapy. Int J STD AIDS 13(8): 522 539.

77. Donders GG (2002) Lower genital tract infections in diabetic women. Curr Infect Dis Rep 4(6): 536-539.

78. Reed BD (1992) Risk factors for Candida Vulvovaginitis. Obstet Gynecol Surv 47(8): 551-560.

79. Spacek J, Jilek P, Buchta V, Förstl M, Hronek M, et al. (2005) The serum levels of calcium, magnesium, iron and zinc in patients with recurrent vulvovaginal candidosis during attack, remission and in healthy controls. Mycoses 48(6): 391-395.

80. Witkin SS (1993) Immunology of the vagina. Clin Obstet Gyneco 36(1): 122-128.

81. Peters BM, Yano J, Noverr MC, Fidel PL (2014) Candida Vaginitis: When Opportunism Knocks, the Host Responds. PLoS Pathog 10(4): e1003965.

82. Romani L (1997) The T cell response against fungal infections. Curr Opin Immunol 9(4): 484-490.

83. Lilic D (2012) Unravelling fungal immunity through primary immune deficiencies. Curr Opin Microbiol 15(4): 420-426.

84. Neves NA, Carvalho LP, De Oliveira MA, Giraldo PC, Bacellar O, et al. (2005) Association between atopy and recurrent vaginal candidosis. Clin Exp Immunol 142(1): 167-171. 
85. Clancy R, Corrigan E, Dunkley M, Eyers F, Beagley K (1999) Recurrent Vulvovaginal candidiasis-allergy or immune deficiency? Int Arch Allergy Immunol 118(2-4): 349-350.

86. Carvalho LP, Bacellar O, Neves NA, de Jesus AR, Carvalho EM (2002) Down- regulation of IFN-gamma production in patients with recurrent vaginal candidiasis. J Allergy Clin Immunol 109(1): 102-105.

87. Moraes PS, Taketomi EA (2000) Allergic vulvovaginitis. Ann Allergy Asthma Immunol 85(4): 253-265.

88. White, Vanthuyne DJA, Wood PM, Ayres JG (2004) Zafirlukast for severe recurrent vulvovaginal candidiasis: an open label pilot study. Sex Transm Infect 80(3): 219-222.

89. Richter SS, Galask RP, Messer SA, Hollis RJ, Diekema DJ, et al. (2005) Antifungal susceptibilities of Candida species causing vulvovaginitis and epidemiology of recurrent cases. J Clin Microbiol 43(5): 2155-2162.

90. Chong PP, Lee YL, Tan BC, Ng KP (2003) Genetic relatedness of Candida strains isolated from women with vaginal candidiasis in Malaysia. J Med Microbiol 52(pt 8): 657-666.

91. Soll DR, Galask R, Isley S, Rao TV, Stone D, et al. (1989) Switching of Candida albicans during successive episodes of recurrent vaginitis. J Clin Microbiol 27(4): 681-690.

92. Schroppel K, Rotman M, Galask R, Mac K, Soll DR (1994) Evolution and replacement of Candida albicans strains during recurrent vaginitis demonstrated by DNA fingerprinting. J Clin Microbiol 32(11): 2646-2654

93. Biswas S, Van Dijck P, Datta A (2007) Environmental Sensing and Signal Transduction Pathways Regulating Morphopathogenic Determinants of Candida albicans. Microbiol Molec Biol Rev 71(2): 348-376.

94. Sobel JD, Chaim W, Nagappan V, Leaman D (2003) Treatment of vaginitis caused by Candida glabrata: use of topical boric acid and flucytosine. Am J Obstet Gynecol 189(5): 1297-1300.

95. Cernicka J, Subik J (2006) Resistance mechanisms in fluconazoleresistant Candida albicans isolates from vaginal candidiasis. Int J Antimi- crob Agents 27(5): 403-408.

96. Eckert LO (2006) Acute vulvovaginitis. N Engl J Med 355: 1244 1252.

97. Ringdahl EN (2006) Recurrent vulvovaginal candidiasis. Mo Med 103(2): 165-168

98. Marchaim D, Lemanek L, Bheemreddy S, Kaye KS, Sobel JD (2012) Fluconazole-Resistant Candida albicans vulvovaginitis. Obstet Gynecol 120(6): 1407-1414.

99. Walker PP, Reynolds MT, Ashbee HR, Brown C, Evans E (2000) Vaginal yeast in the era of the "over-the-counter" antifungals. Sex Trans Infect 76(6): 437-438.

100. Vermitsky JP, Edlind TD (2004) Azole resistance in Candida glabrata: coordinate up-regulation of multidrug transporters and evidence for a Pdr1-like transcription factor. Antimicrob Agents Chemother 48(10): 3773-3781.

101. Sobel J (1993) Candidal vulvovaginitis. Clin Obstet Gynecol 36(1) 153-165.

102. McClelland RS, Richardson BA, Hassan WM, Graham SM, Kiarie J, et al. (2009) Prospective study of vaginal bacterial flora and other risk factors for vulvovaginal candidiasis. J Infect Dis 199(12): 18831890.

103. Erdem H, Cetin M, Timuroglu T, Cetin A, Yanar 0, et al. (2003) Identification of yeasts in public hospital primary care patients with or without clinical vaginitis. Aust N Z J Obstet Gynaecol 43(4): 312-316.

104. Novikova N, Mårdh PA (2002) Characterization of women with a history of recurrent vulvovaginal candidosis. Acta Obstet Gyneco Scand 81(11): 1047-1052.

105. Jelovsek FR (2010) Signs and symptoms of vulvovaginal candidiasis.

106. Hoffstetter SE, Barr S, LeFevre C, Leong FC, Leet T (2008) Selfreported yeast symptoms compared with clinical wet mount analysis and vaginal yeast culture in a specialty clinic setting. J Reprod Med 53(6): 402-406.

107. Martins HPR, Da Silva MC, Paiva LCF, Svidzinski TIE, Consolaro MEL (2012) Efficacy of fluconazole and nystatin in the treatment of vaginal Candida species. Acta Derm Venereol 92(1): 78-82.

108. Zdolsek B, Hellberg D, Fröman G, Nilsson S, Mårdh PA (1995) Vaginal microbiological flora and sexually transmitted diseases in women with recurrent and current vulvovaginal candidosis. Infec 23(2): 81-88.

109. Eckert LO, Hawes SE, Stevens CE, Koutsky LA, Eschenbach DA, et al. (1998) Vulvovaginal candidiasis: clinical manifestations, risk factors, management algorithm. Obstet Gynecol 92(5): 757-765.

110. Sonnex C, Lefort W (1999) Microscopic features of vaginal candidiasis and their relation to symptomatology. Sexually transmitted infections 75(6): 417-419.

111. Workowski KA, Berman S, CDC (2010) Sexually transmitted diseases treatment guidelines. MMWR 59(RR-12): 1-110.

112. Weissenbacher T, Witkin SS, Ledger WJ, Tolbert V, Gingelmaier A, et al. (2009) Relationship between clinical diagnosis of recurrentvulvovaginal candidiasis and detection of Candida species by culture and polymerase chain reaction. Arch Gynecol Obstet 279(2): 125-129.

113. Trama JP, Raphaelli A, Stemmer SM, Mordechai E (2005) Detection of candida species in vaginal samples in a clinical laboratory setting. infectious diseases in obstetrics and gynecology 13(2): 6367.

114. Luo G, Mitchell TG (2002) Rapid identification of pathogenic fung directly from cultures by using multiplex PCR. J Clin Microbiol 40(8): 2860-2865.

115. Sobel JD, Wiesenfeld HC, Martens M, Danna P, Hooton TM, et al (2004) Maintenance fluconazole therapy for recurrent vulvovaginal candidiasis. N Engl J Med 351(9): 876-883.

116. Watson C, Calbretto H (2007) Comprehensive review of conventional and non-conventional methods of management of recurrent vulvovaginal candidiasis. Aust N Z J Obstet Gynaecol 47(4): 262-272.

117. Donders GG, Bellen G, Mendling W (2010) Management of recurrent vulvo-vaginal candidosis as a chronic illness. Gynecol Obstet Invest 70(4): 306-321.

118. Young GL, Jewell D (2001) Topical treatment for vaginal candidiasis (thrush) in pregnancy. Cochrane Database Syst Rev 4: CD000225. 
119. KalliomäkiM, Salminen S, Arvilommi H, Kero P, Koskinen P, et al. (2001) Probiotics in primary prevention of atopic disease: a randomised placebo-controlled trial. The Lancet 357(9262): 10761079.

120. Vicariotto F, Del Piano M, Mogna L, Mogna G (2012) Effectiveness of the association of 2 probiotic strains formulated in a slow release vaginal product, in women affected by vulvovaginal candidiasis: a pilot study. J Clin Gastroenterol. 46 (Suppl): S73-S80.

121. van de Veerdonk FL, Netea MG, Joosten LA, van der Meer JW, Kullberg BJ (2010) Novel strategies for the prevention and treatment of Candida infections: the potential of immunotherapy. FEMS Microbiol Rev 34(6): 1063-1075.

122. Amouri I, Hadrich I, Abbes S, Sellami H, Ayadi A (2013) [Local humoral immunity in vulvovaginal candidiasis]. Ann Biol Clin (Paris) 71(2): 151-155.

123. Rathod SD, Buffler PA (2014) Highly-cited estimates of the cumulative incidence and recurrence of vulvovaginal candidiasis are inadequately documented. BMC Women's Health 14: 43.

124. Hamad M, Kazandji N, Awadallah S, Allam H (2014) Prevalence and epidemiological characteristics of vaginal candidiasis in the UAE. Mycoses 57(3): 184-190

125. Corrigan EM, Clancy RL, Dunkley ML, Eyers FM, Beagley KW (1998) Cellular immunity in recurrent vulvovaginal candidiasis. Clin Exp Immunol 111(3): 574-578.

126. Foxman B, Marsh JV, Gillespie B, Sobel JD (1998) Frequency and response to vaginal symptoms among white and African American women: results of a random digit dialing survey. J Womens Health 7(9): 1167-1174

127. Huang M, McClellan M, Berman J, Kao KC (2011) Evolutionary Dynamics of Candida albicans during In Vitro Evolution Eukaryot Cell 10(11): 1413-1421.

128. Rollenhagen C, Wöllert T, Langford GM, Sundstrom P (2009) Stimulation of cell motility and expression of late markers of differentiation in human oral keratinocytes by Candida albicans. Cell Microbiol 11(6): 946-966.

129. Laga M, Manoka A, Kivuvu M, Malele B, Tuliza M, et al. (1993) Nonulcerative sexually transmitted diseases as risk factors for HIV-1 transmission in women: results from a cohort study. AIDS 7(1): 95-102.

130. Nissapatorn V, Lee C, Fatt QK, Abdullah KA (2004) AIDS- related opportunistic infections in Hospital Kuala Lumpur. Jpn J Infect Dis 56(5-6): 87-192.

131. Singh A, Bairy I, Shivananda PG (2003) Spectrum of opportunistic infections in AIDS cases. Indian J Med Sci 57(1): 16-21.

132. Spinillo A, Michelone G, Cavanna C, Colonna L, Capuzzo E, et al. (1994) Clinical and microbiological characteristics of symptomatic vulvovaginal candidiasis in HIV-seropositive women. Genitourin Med 70(4): 268-272.
133. Kapiga SH, Lyamuya EF, Lwihula GK, Hunter DJ (1998) The incidence of HIV infection among women using family planning methods in Dar es Salaam, Tanzania. AIDS 12(1): 75-84.

134. Røttingen JA, Cameron DW, Garnett GP (2001) A systematic review of the epidemiologic interactions between classic sexually transmitted diseases and HIV: how much really is known? Sex Transm Dis 28(10): 579-597.

135. Wang CC, McClelland RS, Reilly M, Overbaugh J, Emery SR, (2001) The effect of treatment of vaginal infections on shedding of human immunodeficiency virus type 1. J Infect Dis 183(7): 1017-1022.

136. Simon V, Ho DD, Abdool Karim Q (2006) HIV/AIDS epidemiology pathogenesis, prevention and treatment. Lancet 368(9534): 489504

137. Goel V, Bhalla P, Sharma A, Mala YM (2011) Lower genital tract infections in HIV-seropositive women in India. Indian J Sex Transm Dis 32(2): 103-107.

138. Horowitz BJ, Edelstein SW, Lippman L (1987) Sexual transmission of Candida. Obstet Gynecol 69(6): 883-886.

139. Lockhart SR, Reed BD, Pierson CL, Soll DR (1996) Most frequent scenario for recurrent Candida vaginitis is strain maintenance with "substrain shuffling": demonstration by sequential DNA fingerprinting with probes Ca3, C1, and CARE2. J Clin Microbiol 34(4): 767-77.

140. Pirotta M, Gunn J, Chondros P, Grover S, O’Malley P, et al. (2004) Effect of lactobacillus in preventing post-antibiotic vulvovaginal candidiasis: a randomised controlled trial. BMJ 329(7465): 548.

141. Cassone A, De Bernardis F, Santoni G (2007) Anticandidal immunity and vaginitis: novel opportunities for immune intervention. Infect Immun 75(10): 4675-4686.

142. Snydman DR (2003) Shifting patterns in the epidemiology of nosocomial Candida infections. Chest 123(5): 500-503.

143. MacNeill C, Carey JC (2001) Recurrent vulvovaginal candidiasis Curr Womens Health Rep 1(1): 31-35.

144. Ribeiro MA, Dietze R, Paula CR, Da Matta DA, Colombo AL (2000) Susceptibility profile of vaginal yeast isolates from Brazil. Mycopathologia 151(1): 5-10.

145. Fichtenbaum CJ, Koletar S, Yiannoutsos C, Holland F, Pottage J et al. (2000) Refractory mucosal candidiasis in advanced human immunodeficiency virus infection. Clin Infect Dis 30(5): 749-756.

146. Martinez RC, Franceschini SA, Patta MC, Quintana SM, Candido RC, et al. (2009) Improved treatment of vulvovaginal candidiasis with fluconazole plus probiotic Lactobacillus rhamnosus GR-1 and Lactobacillus reuteri RC-14. Lett Appl Microbiol 48(3): 269-274.

147. Falagas ME, Betsi GI, Athanasiou S (2006) Probiotics for prevention of recurrent vulvovaginal candidiasis: a review Journal of Antimicrobial Chemotherapy 58(2): 266-272.

148. Murina F, Graziottin A, Felice R, Radici GL, Di Francesco S (2011) The recurrent vulvovaginal candidiasis: proposal of apersonalized therapeutic protocol. (Abstract) Obstet Gynecol 2011: 806065. 